\title{
Longus colli calcific acute tendinitis: typical features with distinct imaging modalities
}

\author{
Tendinite calcificada aguda do longus colli: características típicas com métodos de \\ imagem distintos \\ Celi Santos Andrade ${ }^{1}$, Cyro Alberto Ramos Peixoto ${ }^{2}$, Flávia Kalil Issa Cevasco ${ }^{1,2}$, Maíra de Oliveira Sarpi ${ }^{1,2}$, \\ Pedro Alberto Arlant ${ }^{3}$
}

A 54-year-old male patient complained of recent acute onset of severe neck pain and stiffness. MR revealed a retropharyngeal effusion and edematous infiltration of the longus colli (Figure 1). Radiographs and CT demonstrated calcifications anterior to C1-C2 (Figure 2). The patient shortly recovered after treatment with corticosteroids.
Tendinitis of the longus colli, also known as retropharyngeal tendinitis, is a rare nonsurgical condition caused by intratendinous deposition of hydroxyapatite calcium ${ }^{1,2,3}$. Although CT may easily depict the pathognomonic calcification, it is important to recognize this benign disease with $\mathrm{MR}$, because this is frequently becoming the first imaging modality for suspected spinal disease ${ }^{3,4,5}$.
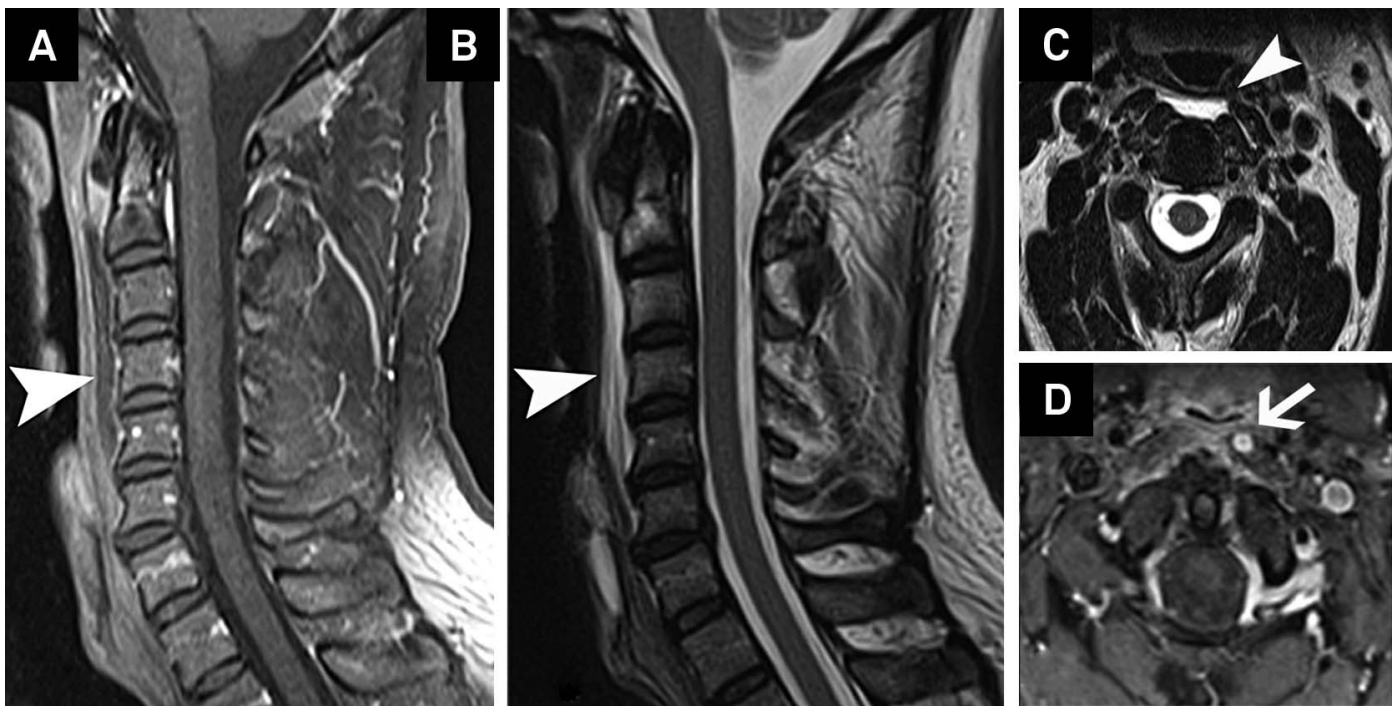

Figure 1. (A) MR exhibits typical findings of acute calcific prevertebral tendinitis. T1-enhanced and (B and C) T2-weighted images demonstrate enhancement and edematous infiltration of the prevertebral soft tissues anterior to C1-C2, as well as a retropharyngeal effusion extending from C2 to C6 (arrowheads); and (D) A focus of gadolinium-enhancement is depicted in the left superior oblique fibers on the longus colli muscle (arrow).

'Departamento de Radiologia, Faculdade de Medicina, Universidade de São Paulo, Sao Paulo SP, Brazil; ${ }^{2}$ Grupo de Neurorradiologia em Cabeça e Pescoço, Centro de Diagnósticos Brasil, Sao Paulo SP, Brazil; ${ }^{3}$ Departamento de Neurologia, Hospital Sírio Libanês, Sao Paulo SP, Brazil.

Correspondence: Celi Santos Andrade; Av. Dr. Enéas de Carvalho Aguiar, 255; 05403-900 São Paulo SP, Brasil; E-mail: celi.andrade@usp.br Conflict of interest: There is no conflict of interest to declare.

Received 06 August 2014; Received in final form 09 September 2014; Accepted 29 September 2014. 

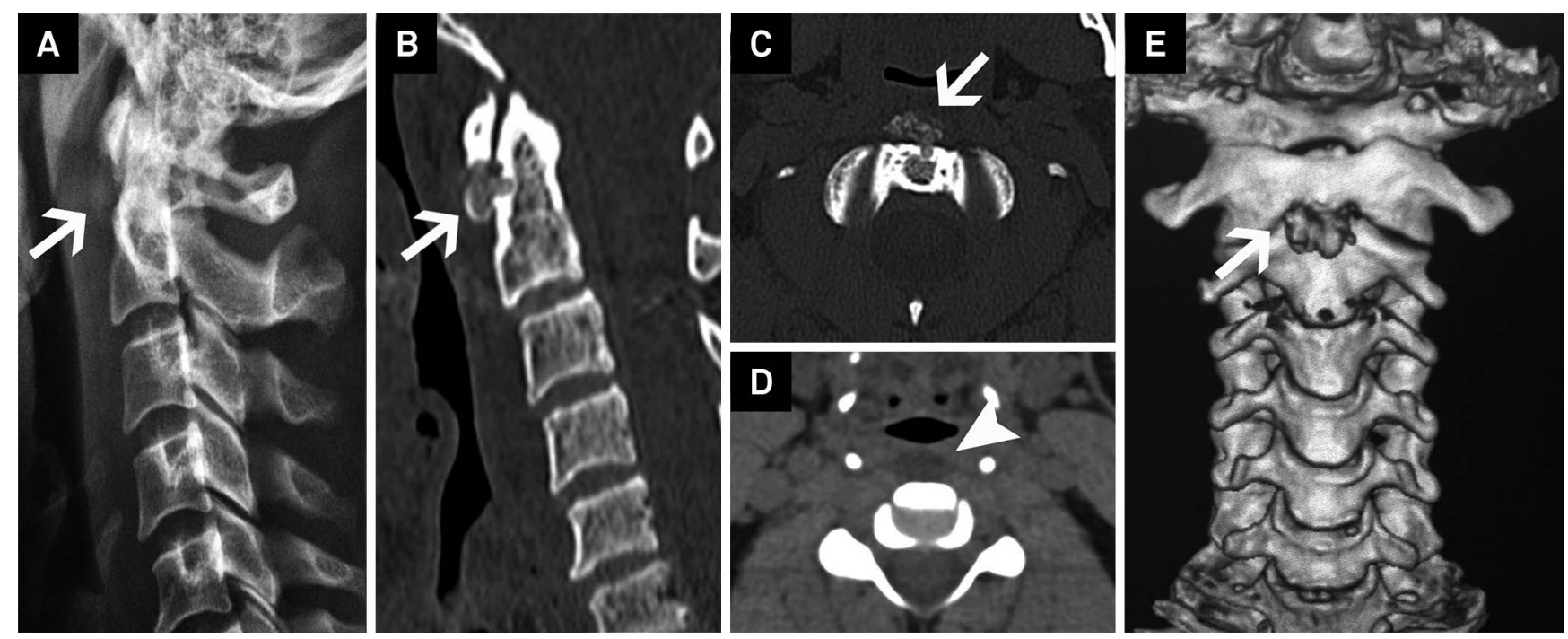

Figure 2. (A) Lateral radiography and (B and C) reformatted CT demonstrate an amorphous calcification (arrows) beneath the anterior arch of C1 and a slight intra-osseous migration with cortical erosion in the anterior margin of C2; (D) Note effacement of the prevertebral tissues, as well as a retropharyngeal effusion (arrowhead); and (E) A 3D bone reconstruction exhibits the pathognomonic calcification (arrow).

\section{References}

1. Bladt O, Vanhoenacker P, Bevernage C, Van Orshoven M, Van Hoe L, D’Haenens P. Acute calcific prevertebral tendinitis. JBR-BTR. 2008;91:158-9

2. esmots F, Derkenne R, Couppey N, Martin B, Gabaudan C, Geffroy Y. Calcific retropharyngeal tendinitis of the longus colli muscle. Diagn Interv Imaging. 2013;94(3):470-3. http://dx.doi.org/10.1016/j.diii. 2012.09.006

3. Eastwood JD, Hudgins PA, Malone D. Retropharyngeal effusion in acute calcific prevertebral tendinitis: diagnosis with CT and MR imaging. AJNR Am J Neuroradiol. 1998;19(9):1789-92.
4. Mihmanli I, Karaarslan E, Kanberoglu K. Inflammation of vertebral bone associated with acute calcific tendinitis of the longus colli muscle. J Neuroradiology. 2001;43(12):1098-101. http://dx.doi.org/ $10.1007 / s 002340100644$

5. Roldan CJ, Carlson PJ. Longus colli tendonitis, clinical consequences of a misdiagnosis. AM J Emer Med 2013;31(10):1538.e1-2. http://dx. doi.org/10.1016/j.ajem.2013.05.035 